\title{
Tauco, Perpaduan Rasa yang Eksotis
}

\author{
Nurul Sukma Lestari ${ }^{1)}$, Jessica Glory Aprillia ${ }^{2)}$ \\ Hotel Management Department, Faculty of Economic and Communication 1,2) \\ Bina Nusantara University, Jakarta, Indonesia 11480 \\ E-mail:nurul.lestari@binus.edu
}

\begin{abstract}
Abstrak
Makanan merupakan salah satu cara untuk meningkatkan Pariwisata di suatu daerah. Banyak wisatawan yang datang ke suatu daerah karena ingin mencoba makanan khas dari daerah tersebut. Indonesia kaya akan makanan khas dari tiap daerah, salah satunya adalah Tauco. Tauco merupakan ikonik dari Kota Cianjur. Tauco adalah makanan berfermentasi yang berfungsi sebagai bumbu dalam masakan. Dengan seiring jaman, bangsa Cina yang tinggal dan menetap mulai memperkenalkan Tauco kepada masyarakat setempat. Tetapi karena rasa asli Tauco kurang digemari oleh masyarakat setempat, maka rasa Tauco mulai mengalami perubahan untuk menyesuaikan dengan rasa yang dikenal oleh masyarakat setempat. Perlu untuk mengetahui jejak sejarah dari tiap makanan tradisional agar kita dapat menjaga dan melestarikan serta memperkenalkan ke dunia luar. Tujuan dari penelitian ini adalah untuk mengetahui sejarah dari Tauco, cara pembuatan tauco dan bagaimana eksistesinya saat ini. Metode penelitian yang digunakan adalah kualitatif dan melakukan pengumpulan data dengan cara wawancara, kuisioner dan studi literatur. Nara sumber adalah pemilik pabrik tauco yang merupakan keturunan keempat dari generasinya dan pemilik rumah makan yang sudah berkecimpung di dunia restoran selama 68 tahun. Sedangkan untuk responden kuisioner didapatkan 100 orang yang berasal dari berbagai kota. Hasil dari penelitian ini didapatkan bahwa Tauco dibawa pertama kali ke kota Cianjur oleh bangsa Tiongkok (China) pada masa penjajahan Belanda yang kemudian berasimilasi dengan rasa lokal sehingga dapat diterima dan disenangi oleh masyarakat. Cara pembuatan masih menggunakan cara tradisional, terutama proses pengeringan yang masih menggunakan sinar matahari, menggunakan kendi tanah liat yang sudah berumur ratusan tahun dan cara pemasakan yang manggunakan kayu bakar. Sedangkan eksistensi tauco sampai saat ini masih banyak berada di generasi tua. Karenanya disarankan untuk lebih memperkenalkan masakan tradisional seperti tauco kepada generasi muda, bisa melalui seminar atau pengetahuan tambahan yang diberikan di sekolah. Agar generasi muda dapat mengenal, menyukai dan ikut menjaga masakan khas daerahnya.
\end{abstract}

Keyword : Tauco, Makanan Khas, Asimilasi

\section{Tauco, a blend of exotic flavors}

\begin{abstract}
Food is one way to increase tourism. Because sometimes tourists come to specific area because they want to try special foods from that area. Indonesia is rich in specialties from each region, one of which is Tauco. Tauco is an iconic of Cianjur. Tauco is a fermented food that serves as a spice in cooking. Derived from soybeans through a long process because it still uses the traditional method so that it becomes a cooking spice that can be used to cook various kinds of food ingredients such as fish, vegetables, chicken, and many more. The purpose of this research is to know the history of Tauco, how to make tauco and how it exists today. The research method used is qualitative and performs data collection by interviews, questionnaires and literature studies. The resource person is a tauco factory owner who is the fourth descendant of his generation and a restaurant owner who has been in the restaurant world for 68 years. Meanwhile, for the questionnaire respondents, it was found that 100 people came from various cities. The results of this study found that Tauco was first brought to the city of Cianjur by the Chinese during the Dutch colonial period which then assimilated it with a local taste so that it could be accepted and liked by the community. The manufacturing method still uses traditional methods, especially the drying process which still uses sunlight, using a clay jug that is hundreds of years old and the cooking method using firewood. Meanwhile, the existence of tauco is still in the older generation. Therefore, it is advisable to introduce more traditional dishes such as
\end{abstract}


tauco to the younger generation, through seminars or additional knowledge given at school. So that the younger generation can get to know, like and take part in preserving their regional specialties.

\section{Keyword: Tauco, Specialty Food, Assimilation}

\section{PENDAHULUAN}

Makanan tradisional atau makanan lokal merupakan salah satu ciri khas dari suatu daerah atau masyarakat tertentu yang dapat membedakan antara satu daerah dengan daerah lain (Tyas, 2017). Indonesia merupakan negara kepulauan yang sangat besar dan setiap wilayahnya memiliki kekayaan kuliner yang menjadi ciri khas atau identitas daerah tersebut (Lestari (A) \& Christina, 2018). Kekayaan masakan Indonesia sangatlah beragam. Setiap masakan memiliki cirikhasnya masing-masing. Ciri dari masakan suatu daerah dapat ditentukan dari rasa, bumbu, dan bahan yang digunakan yang tidak terlepas dari latarbelakang budaya, agama, hingga bangsa asing yang datang untuk berdagang maupun sebagai penjajah (Tim Buku TEMPO, 2015). Dalam penelitian yang terdahulu, Lestari dan Natalina menyatakan bahwa banyak makanan dan minuman tradisional yang terkait erat dengan budaya, atau dapat dikatakan telah melekat erat pada sebuah area/lokasi (Lestari (B), 2020)

Akibat dari banyaknya bangsa asing yang datang ke Indonesia seperti Portugis, Belanda, Spanyol, Tiongkok, India, maka terjadilah akulturasi diberbagai hal salah satunya adalah pada kuliner Indonesia (Rahman, 2016). Salah satu bangsa asing yang banyak memberikan pengaruh terhadap masakan Indonesia adalah bangsa Cina, karena bangsa Cina sudah ada di Indonesia sejak abad ke 13 (Molodysky, 2019). Bahkan menurut Fadly Rahman di dalam bukunya Jejak Rasa Nusantara mengemukakan bahwa di dalam prasasti Watukura (bertarikh 824c/902 M) sudah menyebutkan kata tahu, dimana tahu merupakan pengaruh dari Tiongkok (Rahman, 2016). Ratusan tahun sudah bangsa Cina tinggal dan berbaur dengan bangsa Indonesia, sehingga sudah terjadi akulturasi yang berpengaruh terhadap kebudayaan, pakaian, agama dan juga kuliner/makanan di berbagai daerah di Indonesia.

Awal masuknya bangsa Cina ke Indonesia adalah karena jalur perdagangan. Hubungan perdagangan yang terjadi selama berabad-abad ini menyebabkan banyaknya bangsa Cina yang mulai menetap dan menikah dengan penduduk lokal di berbagai daerah dan keturunannya disebut dengan Cina Peranakan (Gumulya, 2017). Ada beberapa daerah yang memiliki mayoritas etnis Cina, seperti Bangka Belitung yang memiliki 30\% penduduk keturunan Cina, Kalimantan Barat (Pontianak dan Singkawang), Medan dan juga Jawa (SuaraMerdeka.com, 2019). Ada berbagai macam masakan Indonesia yang merupakan akulturasi atau bersumber dari masakan Cina, seperti, Sekoteng, Nasi goreng, Soto (Aflakhah, 2017). Bakmie, Lumpia Semarang, Kue Bulan, kue tiong jiu pia (Soegihartono, 2015), Tauco sebagai olahan dari kacang kedelai (Mutiara, Nurhasanah, \& Nashar, 2018), dan masih banyak lagi.

Tauco atau fermentasi dari kacang kedelai ini banyak digunakan sebagai penyedap atau bahan tambahan dalam makanan tradisional dari beberapa daerah di Indonesia (L.W, 2011). Tauco memiliki rasa yang khas sebagai bumbu masakan yang dihasilkan dari proses fermentasi, selain rasa proses ini juga memberikan warna, aroma dan tekstur yang berbeda (Djayasupena, Korinna, Rachman, \& Pratomo, 2014). Ada beberapa daerah yang memiliki tauco dan menggunakannya di dalam masakan daerah tersebut seperti, Pekalongan, Medan, Padang, Cirebon, Cianjur dan beberapa daerah lainnya (Bromokusumo, 2011)

Masakan dapat menjadi identitas dari suatu bangsa (Masduki, 2017), maka sangat penting untuk mengetahui sejarah dan perkembangan masakan tradisional yang ada di tiap daerah di Indonesia. Sejalan dengan perkembangan pariwisata saat ini terutama di dalam wisata kuliner yang dapat menarik minat wisatawan untuk berkunjung ke suatu daerah dan mencoba masakah khas dari daerah tersebut (Nugroho \& Hardani, 2020). Wisata makanan atau yang dikenal dengan wisata kuliner dalam beberapa tahun terakhir telah berkembang pesat dan telah menjadi salah satu segmen pariwisata yang paling dinamis dan kreatif, dan telah mendorong diversifikasi pariwisata dan merangsang perkembangan lokal, ekonomi regional dan nasional (World Tourism Organization, 2012). Produk makanan dan minuman memberikan kontribusi 
$19,33 \%$ dari total pendapatan di bidang Pariwisata di indonesia (Tanico, 2016).

Adapun tujuan dari penelitian ini adalah untuk mengetahui beberapa hal terkait dengan ikon Kota Cianjur yaitu Tauco dilihat melalui ilmu gastronomi, yaitu (1) Sejarah Tauco, (2) Cara pembuatan dan (3) Bagaimanakah eksistensi Tauco saat ini.

\section{KAJIAN PUSTAKA \\ Sejarah Masuknya Bangsa Cina Di Cianjur}

Jika ditelaah dari sejarah, bangsa Cina (Tionghoa) datang ke Indonesia dengan maksud untuk berdagang, penyebaran agama Budha, dan berbagi pengetahuan tentang sastra yang dimulai sejak masa Dinasti Han (206 SM - 220 M). Selain dengan Indonesia bangsa Cina juga berdagang dengan negaranegara lain yang ada di Asia Tenggara. Dan pada masa Dinasti Tang $(618-907 \mathrm{M})$ terdapat orang-orang Tionghoa di Kerajaan Sriwijaya (Yuanzhi, 2005).

Menurut sejarawan Pater Carey, bangsa Cina (Tiongkok) yang pada awalnya hanyalah untuk berdagang barang-barang dari negaranya ke Indonesia, beberapa diantaranya mulai berbaur dan menetap di Indonesia dan tidak sedikit yang menikah dengan penduduk lokal (Tifada \& Mahabarata, 2020)

Pada awal abad ke 19, pasca terjadinya pembantaian terhadap bangsa Cina di Batavia mereka memilih untuk memberontak dan melawan penjajah yang berakibat menurunnya jumlah populasi bangsa Cina di Batavia. Karena penurunan jumlah populasi yang sangat besar maka bangsa Cina mulai hidup menyebar dan masuk ke daerah sekitar Batavia seperti Bogor dan Cianjur, yang dipimpin oleh Kapitan dari Bogor bernama Oey Seng Kiat (Nurcahya, 2017). Berdasarkan belsuit tanggal 9 Juni 1810, ada beberapa kota seperti Cianjur, Parakan-muncang, Sumedang, Sukapura, Limbangan, dan Galuh yang berada di keresidenan Priangan yang menjadi Pecinan (Chineesche kamp), dimana Pecinan ini dibentuk oleh pemerintahan Belanda yang dimaksudkan untuk memberdayakan lahan kosong dengan menggiatkan perdagangan untuk meningkatkan kesejahteraan masyarakat (Kustedja, 2012).

Dengan banyaknya bangsa Cina yang tinggal dan menetap maka terjadi pembauran antara masyarakat lokal dengan segala sesuatu yang dibawa oleh etnis Cina yang dikenal sebagai akulturasi (Sari, 2019). Pengaruh bangsa Cina yang dikenalkan kepada masyarakat lokal salahsatunya adalah dalam pengolahan suatu makanan atau memperkenalkan makanan yang biasa mereka produksi dan konsumsi (Wardana, 2017).

\section{Makanan Tradisional}

Makanan tradisional atau makanan lokal adalah suatu identitas dari sekelompok orang atau masyarakat yang sangat mudah ditemukan dan dikenali (Tyas, 2017). Makanan lokal/setempat merupakan bagian penting dari gastronomi karena itu tidak hanya memberikan pengalaman tetapi juga menghubungkan segala sesuatu yang menyertainya seperti budaya, sejarah, seni, dan kesehatan (Nariani, 2019). Makanan Lokal memiliki ciri khas yang membuat wisatawan ingin mencoba dan menikmati rasa, sensasi dan penyajiannya yang sesuai dengan tradisi masa lampau (Yanthy, 2016)

Makanan lokal dapat mencerminkan alam sekitar, keadaan daerah setempat dan masyarakatnya sehingga dapat disimpulkan bahwa ada hubungan yang erat antara Pariwisata dan produksi dari makanan lokal (Putra, 2014). Makanan tradisional memiliki beberapa kriteria, yaitu: (1) biasa dikonsumsi selama beberapa generasi, (2) memiliki rasa yang begitu sesuai dengan selera masyarakat, (3) tidak bertentangan dengan agama, kepercayaan, dan kepercayaan masyarakat setempat, (4) dibuat dari bahan makanan dan bumbu yang tersedia di sekitar lingkungan setempat (Muliani, 2019).

\section{Wisata Makanan/wisata kuliner}

Wisata makanan adalah sebuah pengalaman perjalanan ke kawasan gastronomi, untuk rekreasi atau tujuan hiburan, yang mencakup kunjungan ke produsen makanan, festival gastronomi, pameran makanan, acara, pasar petani, pertunjukan memasak dan demonstrasi, mencicipi produk makanan berkualitas atau aktivitas pariwisata apa pun terkait dengan makanan (Hall \& Sharples, 2003).

Yang termasuk di dalam Wisata kuliner adalah nilai-nilai etis yang berkelanjutan berdasarkan wilayah, lanskap, laut, budaya lokal, produk lokal, dan keaslian, yang memiliki kesamaan dengan tren konsumsi budaya saat ini (Rifai, 2012). Wisata kuliner dapat menjadi suatu strategi yang digunaan dalam pengembangan pariwisata di suatu kota (Wijayanti, 2020) selain itu dapat menjadi salah satu daya tarik wisatawan untuk menunjungi suatu daerah (Kristiana, Suryadi, \& Sunarya, 2018)

Wisata kuliner didominasi oleh lima tema yaitu motivasi, budaya, keaslian, 
manajemen dan pemasaran, serta orientasi destinasi (Ellis, Park, Kim, \& Yeoman, 2018). Bagi wisatawan kuliner, makanan adalah identitas. Dimana identitas ini dibentuk oleh keaslian dan pengalaman hedonistik (Yeoman \& McMahon-Beatte, 2016). Wisatawan yang datang ke suatu destinasi pariwisata biasanya ingin menikmati kebudayaan lokal berikut dengan makanan dan minuman tradisional dari daerah tersebut (Kusumawati \& Yogeswara, 2020). Makanan dapat menjadi salah satu daya tarik pariwisata serta mendorong penambahan jumlah wisatawan, memberikan pengalaman dan juga memberikan identitas untuk suatu daerah serta mendorong pertumbuhan pada sektor lainnya (Bhudiharty, Ratnasari, \& Waluyo, 2019).

\section{Gastronomi}

Secara umum gastronomi adalah suatu studi yang mempelajari hubungan antara budaya dan kuliner sebagai pusatnya (Sufa, Subiakto, Octavianti, \& Kusuma, 2020). Suatu pengalaman yang didapat dari makanan mulai dari makanan pembuka hingga makanan penutup dengan mempelajari sejarah, asal usul, bahan-bahan yang digunakan (Kartika \& Harahap , 2019). Gastronomi telah menjadi salah satu yang sumber utama yang menjadi daya tarik destinasi wisata (Galvez, LopezGuzma, Buiza, \& Medina-Viruel, 2017).

Gastronomi memiliki empat komponen yang terkait didalamnya: (Ketaren, 2017), yaitu: (1) Budaya: faktor etnis lokal termasuk agama, kepercayaan, adat istiadat dan tradisi dan nilai-nilai kearifan lokal, (2) Sejarah: asal mula budidaya mentah bahan untuk memasak dan kemampuan untuk berinovasi dalam komponen, tekstur, dan rasa dalam makanan, (3) Lanskap geografis: faktor geografis \& iklim serta tingkat keragaman pendatang lokal dan etnis, (4) Metode memasak: teknik memasak dan proses secara umum.

\section{METODE PENELITIAN}

Metode penelitian yang digunakan adalah kualitif descriptif dengan Teknik pengumpulan data berupa: (1) Studi Literatur, yaitu teknik pengumpulan data yang sesuai dengan objek penelitian yang didapatkan dari buku, jurnal, artikel dan situs-situs di internet. (Sulistyowati, 2016), (2) Wawancara, suatu Teknik pengumpulan data dengan cara mengajukan pertanyaan kepada nara sumber yaitu pemilik pabrik tauco dan pemilik rumah makan yang sudah ada sejak jaman Jepang, (3) Observasi, adalah suatu metode pengumpulan data dengan cara mengamati atau meninjau objek yang diteliti yaitu Tauco Cianjur, (4) Kuisioner, suatu Teknik pengumpulan data dalam bentuk pertanyaan yang harus diisi oleh responden baik secara langsung maupun tidak langsung. Kuisioner ini akan ditujukan kepada generasi muda dengan rentang umur 15 tahun sampai dengan 30 tahun. Responden yang dituju memang dari generasi muda, karena ingin mengetahui pengetahuan mereka tentang eksistensi tauco pada saat ini.

\section{HASIL DAN PEMBAHASAN Sejarah Tauco}

Tauco adalah makanan khas daerah Cianjur yang banyak ditemukan sampai hari ini. Tauco menjadi ikon dari kota Cianjur bahkan sejak 2017 di kota Cianjur terdapat tugu yang berbentuk Botol Tauco yang terletak di jalan Bypass-Cianjur dekat dengan pusat oleh-oleh khas Cianjur (Fikri \& Lantara, 2019). Cianjur merupakan kota industri tauco yang paling lama dan terbesar di Indonesia. Tauco adalah terbuat dari kacang kedelai yang direbus kemudian dihaluskan dan dicampur dengan terigu kemudian dilakukan proses fermentasi.

Wawancara dilakukan kepada pemilik pabrik tauco tertua di Cianjur yang sudah berdiri sejak 1880, Pabrik Tauco Cap Meong, yaitu Ibu Stefany Tasma (ST) yang merupakan generasi keempat dan kepada pemilik rumah makan Moy Tung Ibu Yulianti (Y)

Menurut ibu ST, Sejarah dari tauco berasal dari orang Tionghoa yang datang ke Indonesia dan menyebar ke Cianjur. Pada awalnya orang Tionghoa datang untuk berdagang dan kemudian lama kelamaan jadi tinggal menetap dan memperkenalkan kebudayaan mereka. Awal masuknya orang Tionghoa ke Cianjur adalah pada tahun 1880 an, dan Tauco cap Meong sebagai pelopor pertama yang membuat dan menjual Tauco di Cianjur. Adapun yang membangun pabrik ini adalah nenek buyut dari Ibu ST. Pada awal mulanya tauco hanyalah diminati oleh orangorang Tionghoa yang tinggal di Cianjur, karena rasanya yang masih sangat otentik yaitu manis sehingga kurang disukai oleh masyarakat sekitar. Pada awalnya kakek buyut (Tan Ken Hian) dari Ibu ST menjual tauco buatannya secara berkeliling. Rasa manis yang merupakan rasa asli dari Tauco kurang diminati oleh pembeli dari kalangan masyarakat setempat. Kemudian nenek buyut (Tjoa Kim Nio) dari ibu ST atau yang lebih dikenal dengan Ny. Tasman melakukan penyesuaian rasa agar dapat diterima oleh lidah masyarakat setempat, rasanya diubah 
menjadi asin. Dan sampai sekarang sudah 140 tahun pabrik ini memproduksi tauco dan dapat diterima oleh lidah masyarakat setempat dan masyarakat Indonesia secara luas.

Hal yang sama dikemukakan oleh lbu $Y$ sebagai pemilik rumah makan yang sudah 68 tahun tinggal dan menetap di Cianjur, bahwa tauco merupakan makanan khas orang Tiongkok yang dibawa dan diperkenalkan kepada masyarakat Cianjur dan Indonesia pada umumnya. Pada awalnya orang Tiongkok datang dan berniaga kemudian seiring waktu mulai memperkenalkan kebudayaan dan makanan khas yang kemudian dilakukan perubahan rasa agar dapat beradaptasi dengan lidah masyarakat Cianjur.

Menurut kedua narasumber, tauco memiliki nilai tambah. Menurut lbu ST, rasa tauco yang asli yaitu rasa manis sudah berasimilasi dengan rasa lokal sehingga tauco sekarang ini banyak digemari oleh masyarakat umum, dan tauco sampai saat ini menjadi ciri khas dari kota Cianjur. Sedangkan menurut Ibu $Y$, dengan adanya industri pembuatan tauco, banyak memberi peluang pada masyarakat setempat untuk dapat membuka toko atau berjualan tauco khas Cianjur ini.

\section{Cara pembuatan Tauco}

Untuk proses pembuatan ibu ST yang lebih mengetahui dengan detail, karena beliau pemilik dari pabrik tauco, sedangkan lbu $\mathrm{Y}$ hanyalah mengolah tauco menjadi suatu makanan dan dijual di rumah makannya. Cara pembuatan yang dipakai oleh pabrik tauco Cap Meong masih menggunakan cara tradisional, bahkan beberapa peralatan yang digunakan sudah ada sejak jaman kakek dan nenek buyut dari lbu ST.

Cara pembuatan tauco cukup lama karena masih menggunakan cara tradisional. Pertama yang harus dilakukan adalah menseleksi kacang kedelai yang akan digunakan. Dipilih yang benar-benar berkualitas bagus dan tidak tercampur dengan biji jagung ataupun batu kerikil kecil. Setelah itu kedelai yang telah dipilih dan berkualitas baik di jemur dengan menggunakan sinar matahari sampai kering. Proses bisa memakan waktu dua sampai tiga hari tergantung dari cuaca pada saat penjemuran. Jika kurang sinar matahari maka proses pengeringan ini bisa memakan waktu yang lebih lama. Setelah kedelai kering dilakukan proses penggilingan agar kedelai terbagi menjadi dua bagian. Setelah itu kedelai direbus. Biasanya proses perebusan dilakukan dari jam 08.00 pagi sampai dengan jam 15.00 sore. Proses perebusan pun masih menggunakan cara yang tradisional, yaitu menggunakan kayu bakar.

Setelah proses perebusan, kedelai kembali dijemur sampai kering. Jika panas sedang terik maka hanya diperlukan waktu satu hari untuk proses pengeringan. Setelah kedelai kering, maka dilanjutkan dengan proses Peuyeman. Proses ini memasukan kedelai kedalam satu ruangan selama satu hari untuk proses fermentasi. Setelah itu Kembali dilakukan proses penjemuran sampai kering. Setelah itu kedelai hasil fermentasi yang sudah dikeringkan dimasukan kedalam kendi tanah liat dan diberi air garam. Didalam proses ini digunakan kendi tanah liat yang sudah berumur ratusan tahun atau merupakan warisan dari kakek dan nenek buyut dari lbu ST. Setiap hari kedelai ini diaduk dan dibalik sampai airnya habis. Proses ini biasanya memakan waktu selama dua sampai tiga minggu. Setelah airnya habis proses pembuatan tauco ini baru selesai setengah jadi, atau disebut dengan tauco kering. Proses ini dapat dilihat pada gambar dibawah ini:

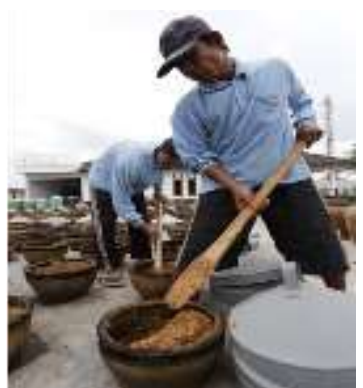

Sumber:Peneliti(2020)

Gambar 1. Proses Pengasinan Tauco

Dari Tauco kering, maka masih ada proses lanjutan agar dapat menjadi tauco yang biasa dijual atau dijadikan oleh-oleh. Tauco kering ini melalui proses pemasakan untuk memberi rasa yang digemari oleh masyarakat pada umumnya. Caranya pada proses pemasakan adanya dengan penambahan gula merah, air, merica dan gula putih. Keseluruhan proses pemasakan dari tauco kering sampai menjadi tauco yang dapat dijual dalam kemasanan berkisar tiga sampai empat jam. Proses pemasakan seperti gambar dibawah ini: 


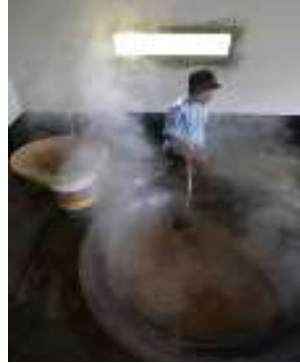

Sumber:(Peneliti (2020)

Gambar 2. Proses Masak Tauco Kering menjadi Tauco Matang

Menurut Ibu ST dari awal pemilihan kedelai sampai dengan menjadi satu kemasan Tauco, proses pembuatan dapat mencapai kurang lebih tiga bulan, dan bisa lebih lama jika cuaca sedang kurang panas. Sebab proses pengeringan masih menggunakan cara tradisional yaitu pengeringan dengan sinar matahari. Proses pengeringan dapat dilihat pada gambar dibawah ini:

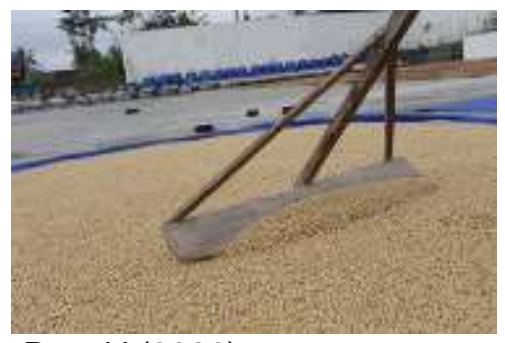

Sumber:Penelti (2020)

Gambar 3. Proses Pengeringan Tauco

Sedangkan menurut lbu Y, beliau hanya mengetahui bahwa kacang kedelai melalui proses fermentasi kemudian dijemur lalu dimasukan kedalam kendi dan ditambahkan air garam setelah itu dibumbui. lbu $Y$ lebih mengetahui cara mengolah tauco menjadi masakan-masakan yang kemudian beliau tawarkan di rumah makannya, salah satu nya adalah Geco (tauge tauco).

\section{Eksistensi Tauco}

Menurut Ibu ST eksistensi dari tauco masih kental, beliau melihat dari minat masyarakat yang masih menjadikan tauco sebagai oleh-oleh selain juga membeli untuk dinikmati sendiri. Tidak sedikit dari pelanggannya yang sering menanyakan tentang cara pembuatan bahkan ada yang menanyakan rasanya seperti apa untuk yang baru pertama melakukan pembelian. Pembelian terbanyak masih pada orang-orang yang sudah lebih berumur dibandingkan dengan anak muda.
Ibu ST menyarankan agar dapat mempertahankan eksistensi dari Tauco yaitu dengan cara memodifikasi masakan yang menggunakan tauco agar sesuai dengan trend saat ini atau sesuai dengan lidah anak muda, misalnya seperti Sambal Tauco. Selain itu dapat juga dibuatkan suatu seminar yang bertujuan untuk memperkenalkan Tauco secara lebih luas lagi.

Sedangkan menurut Ibu $Y$ tidak sedikit tamu yang datang ke rumah makannya setelah menikmati masakan yang ada juga menanyakan apakah rumah makan ibu $Y$ menjual Tauco. Di rumah makan lbu $Y$ memang menjual berbagai oleh-oleh dari Cianjur, tetapi Tauco tidak termasuk di dalamnya.

Saran dari lbu $Y$ untuk menjaga eksistensi dari Tauco adalah dengan cara meluaskan penjualan salah satunya dengan penjualan via online, cara penjualan yang lebih dekat dengan anak muda. Dapat juga membuat bazar di beberapa kota untuk memperkenalkan Tauco dan terus mengingatkan bahwa rasa dari tauco ini sangat enak dan dapat dipadukan dengan beberapa bahan masakan lain.

Selain wawancara, peneliti juga membagikan kuisioner kepada beberapa orang yang berasal dari berbagai kota untuk mengetahui apakah mereka mengetahui tentang tauco. Penyebaran kuisioner dilakukan selama satu minggu dan mendapatkan 100 responden.

Pada tabel dibawah ini dapat dilihat jumlah responden yang mengetahui cara pembuatan tauco secara sederhana.

Tabel 1. Data responden tentang pembuatan tauco secara sederhana

\begin{tabular}{cc}
\hline Pembuatan Tauco & Frekuensi \\
\hline Mengetahui & 69 \\
Tidak & 31 \\
Jumlah Responden & 100 \\
\hline Sumber: Penelit(2020) &
\end{tabular}

Dari 100 responden, yang berasal dari Jakarta, Cianjur, Tangerang, dan beberapa kota lainnya dengan rentang umur 15 sampai dengan 30 tahun, terdapat enam puluh sembilan responden yang mengetahui cara pembuatan tauco secara sederhana dan tiga puluh satu responden tidak mengetahui cara pembuatannya.

Dari kuisioner juga didapatkan data apakah tingkat kesukaan responden dalam mengkonsumsi 
Tabel 2. Tingkat Kesukaan pada Tauco

\begin{tabular}{cc}
\hline $\begin{array}{c}\text { Tingkat kesukaan } \\
\text { terhadap Tauco }\end{array}$ & Frekuensi \\
\hline Menyukai & 69 \\
Tidak & 10 \\
Mungkin & 18 \\
Belum Pernah Mencoba & 3 \\
Jumlah Responden & 100 \\
\hline \multicolumn{2}{c}{ Sumber: Peneliti (2020) }
\end{tabular}

Dari 100 orang responden, ternyata ada sebanyak enam puluh sembilan responden yang menyukai tauco, sepuluh responden tidak menyukai, delapan belas responden menyatakan mungkin menyukai mungkin tidak dan tiga responden menyatakan belum pernah mencobanya. Responden menyukai rasa masakan yang menggunakan tauco karena tauco memberikan rasa yang khas dan sangat berbeda dari masakan lain.

Responden juga diberikan pertanyaan tentang bahan-bahan yang biasa para responden gunakan untuk memasak Tauco.

Tabel 3. Bahan yang digunakan untuk memasak Tauco

\begin{tabular}{cc}
\hline Bahan Masak & Frekuensi \\
\hline Ikan & 36 \\
Sayuran & 28 \\
Ayam & 8 \\
Kodok & 4 \\
Cumi / Udang & 2 \\
Sambal & 1 \\
Tidak Pernah Memasak & 21 \\
Jumlah Responden & 100 \\
\hline \multicolumn{2}{c}{ Sumber: Peneliti (2020) }
\end{tabular}

Dari bahan-bahan yang digunakan untuk memasak dengan menggunakan Tauco paling banyak digunakan oleh responden adalah ikan sebanyak tiga puluh enam responden dan sayur-sayuran sebanyak dua puluh delapan responden. Sisanya ada yang memasak dengan ayam sebanyak delapan responden, memasak dengan kodok sebanyak empat responden, dua responden memasak dengan udang/cumi dan sisanya dua puluh satu responden tidak pernah memasak menggunakan tauco. Hal ini berdasarkan dari pengalaman para responden saat mereka mengolah tauco yang dipadukan dalam masakan sehari-hari.

Yang terakhir adalah lokasi dimana responden melakukan pembelian Tauco. Ada beberapa tempat, seperti tempat pusat oleholeh, pabrik tauco, dan juga oline.

Tabel 4. Lokasi Pembelian Tauco

\begin{tabular}{cc}
\hline Lokasi membeli Tauco & Frekuensi \\
\hline Penjualan Oleh-oleh & 35 \\
Pabrik Tauco & 30 \\
Pembelian Online & 9 \\
Tidak pernah membeli & 26 \\
Jumlah Responden & 100 \\
\hline \multicolumn{2}{c}{ Sumber: Peneliti (2020) }
\end{tabular}

Dari 100 responden, tiga puluh lima responden melakukan pembelian di tempat penjualan oleh-oleh, tiga puluh responden membeli tauco di pabrik Tauco, Sembilan responden melakukan pembelian secara online dan dua puluh enam responden tidak pernah membeli.

\section{PENUTUP}

Dapat disimpulkan berdasarkan hasil wawancara, dan bahan pendukung bahwa Tauco merupakan makanan yang dibawa oleh orang Tionghoa pada saat memasuki kota Cinajur dan berasimilasi dengan rasa lokal. Rasa yang pada awalnya hanyalah manis dan tidak mendapatkan tempat di dalam masakan mayarakat setempat berubah dan menyesuaikan dengan rasa lokal sehingga dapat diterima dan menyatu pada beberapa masakan lokal. Perpaduan dua rasa dari dua budaya inilah yang memunculkan rasa eksotis pada tauco dan tidak ada persamaan dari bahan makanan fermentasi yang lain, sehingga menimbulkan rasa yang sangat khas pada Tauco.

Cara pembuatan yang masih tradisional dilakukan oleh nara sumber yang merupakan pemilik dari pabrik pembuatan tauco untuk menjaga rasa dari tauco agar tidak berubah dari waktu ke waktu. Bukan hanya cara pembuatan tetapi juga beberapa peralatan yang digunakan berasal dari masa kakek dan nenek buyut nara sumber.

Eksistensi dari Tauco dapat disimpulkan dari hasil wawancara, dan data kuisioner yang didapat menunjukan bahwa masih banyak orang yang mengenal dan menyukai tauco. Beberapa yang menjadi usulan untuk menjaga eksistensi Tauco adalah dengan membuat modifikasi masakan yang sesuai dengan generasi muda, membuat seminar untuk memperkenalkan tauco, melakukan perluasan penjualan secara Online dan membuat bazar di beberapa tempat.

Perkembangan dari pariwisata tidak dapat dipisahkan dari peran masyarakat lokal, dibutuhkan dukungan dan partisipasi dari masyarakat (Edison, Kartika, \& Dewi, 2019). Saran yang dapat peneliti berikan kepada produsen Tauco adalah membuat suatu kemasan yang menarik dan ditambahkan sedikit tentang sejarah dari tauco, sehingga 
wisatawan pada saat membeli bisa mengetahui sejarahnya secara singkat. Dan untuk pemerintah daerah diusulkan agar dapat melakukan pembelajaran ke sekolah-sekolah agar generasi muda tetap mengetahui dan menyukai makanan lokal dan diharapkan makanan lokal tidak akan hilang seiring dengan berjalannya waktu.

\section{DAFTAR PUSTAKA}

Aflakhah, M. (2017, February 09). Akulturasi Budaya di Balik Makanan Nusantara. Retrieved from goodnewsfromindonesia.id: https://www.goodnewsfromindonesia.i d/2017/02/09/akulturasi-budaya-dibalik-makanan-nusantara

Bhudiharty, S., Ratnasari, K., \& Waluyo, S. (2019). Analisis Potensi Daya Tarik Wisata Gastronomi di Kawasan Petak Sembilan Glodok, Jakarta Barat. Jurnal Industri Pariwisata, 2(1), 50-58.

Bromokusumo, A. (2011, April 14). Tauco. Retrieved from /web.budayationghoa.net: http://web.budayationghoa.net/index.php/item/669-tauco

Djayasupena, S., Korinna, G., Rachman, S., \& Pratomo, U. (2014). Potensi Tauco sebagai Pangan Fungsional. Chimica et Natura Acta , 2(2), 137-141.

Edison, E., Kartika, T., \& Dewi, N. (2019). Persepsi Masyarakat terhadap Pengembangan Kawasan Wisata di Desa Kertawangi, Cisarua Kabupaten Bandung Barat. Journal of Indonesian Tourism Hospitality and Recreation, 2(2), 138-144.

Ellis, A., Park, E., Kim, S., \& Yeoman, I. (2018). What is food tourism? Tourism Management, 68, 250-263.

Fikri, A., \& Lantara, F. (2019, Mei 12). Pemudik bisa beristirahat sambil berwisata di Cianjur. Retrieved from Antaranew.com:

https://megapolitan.antaranews.com/b erita/60166/pemudik-bisa-beristirahatsambil-berwisata-di-cianjur

Galvez, J., Lopez-Guzma, T., Buiza, F., \& Medina-Viruel, M. (2017). Gastronomy as an element of attraction in a tourist destination: the case of Lima, Peru. Journal of Ethnic Foods, 4(4), 254261.

Gumulya, D. (2017). Pencampuran Budaya Cina, Jawa, dan Belanda pada Budaya Makan Cina Peranakan. ANDHARUPA Jurnal Desain
Komunikasi Visual \& Multimedia, 3(02), 130-143.

Hall, C., \& Sharples, L. (2003). Chapter 1 - The consumption of experiences or the experience of consumption? An introduction to the tourism of taste. In C. Hall, L. Sharples, R. Mitchell, N. Macionis, \& B. Cambourne (Eds.), Food Tourism Around The World: Development, management and markets (pp. 1-24). Elsevier Ltd.

Kartika, T., \& Harahap , Z. (2019). The Culinary Development of Pempek as a Gastronomic Tourist Attraction in Palembang Sumatera Selatan. Tourism Scientific Journal, 4(2), 211233.

Ketaren, I. (2017). Gastronomi Upaboga Indonesia (Vol. 2). Jakarta: Indonesian Gastronomy Association.

Kristiana, Y., Suryadi, M., \& Sunarya, S. (2018). Eksplorasi Potensi Wisata Kuliner Untuk Pengembangan Pariwisata Di Kota Tangerang. Jurnal Khasanah IImu, 9(1), 18-23.

Kustedja, S. (2012). Jejak Komunitas Tionghoa dan Perkembangan Kota Bandung. Jurnal Sosioteknologi , 26(11), 105-128.

Kusumawati, I., \& Yogeswara, I. (2020). Pemanfaatan Loloh Sembung (Blumea Balsamifera) sebagai Welcome Drink. Pariwisata, 7(2), 115-123.

L.W, C. (2011). Re-Branding Tauco Cap Meong Ny. Tasma. Bandung: Universitas Kristen Maranatha.

Lestari (A), N. S., \& Christina. (2018). Doclang, Makanan Tradisional Yang Mulai Tersisihkan. Jurnal Khasanah IImu, 9(2), 21-27.

Lestari (B), N. S. (2020). Roti Gambang, Acculturation Bread from Betawi. Journal of Indonesian Tourism, Hospitality and Recreation (JITHOR), 3(1), 40-48.

Masduki, A. (2017). Makanan Tradisional di Kabupaten Ciamis. Patanjala, 4(2), 8999.

Molodysky, N. (2019). Kuliner Khas Tionghoa Di Indonesia: Rahasia Resep dan Kisah di Baliknya. (N. Khairunnisa, Ed.) VisiMedia.

Muliani, L. (2019). Potensi Bubur Ase sebagai Daya Tarik Wisata Kuliner Jakarta. Destinesia Jurnal Hospitaliti \& Pariwisata, 1(1), 50-56.

Mutiara, J., Nurhasanah, A., \& Nashar. (2018). Perkembangan Industri Tauco Cap Biruang di Kabupaten Cianjur tahun 
1960-1980. Jurnal Candrasangkala, 4(2), 155-160.

Nariani, N. (2019). Pengembangan Kuliner Lokal Berdasarkan Persepsi Wisatawan Di Ubud, Bali. Journey (Journal of Tourismpreneurship, Culinary, Hospitality, Convention and Event Management), 1(2), 85-98.

Nugroho, S., \& Hardani, P. (2020). Gastronomi Makanan Khas Keraton Yogyakarta sebagai Upaya Pengembangan Wisata Kuliner. Pariwisata, 7(1), 5262.

Nurcahya, I. (2017, Maret 31). Dari Tauco Sampai Barongsai, Simbol Penerimaan Kaum Etnis di Cianjur. Retrieved from Kompasiana: https://www.kompasiana.com/intannur cahyaberlatih/58dc96473397735408e b7e16/dari-tauco-sampai-barongsaisimbol-penerimaan-kaum-etnis-dicianjur?page=all\#

Putra, I. (2014). Empat Srikandi Kuliner Bali: Peran Perempuan dalam Pembangunan Pariwisata Berkelanjutan. JUMPA, 01(01), 65-94.

Rahman, F. (2016). Jejak Rasa Nusantara (Sejarah Masakan Indonesia). Jakarta: PT. Gramedia.

Rifai, T. (2012). Global Report on Food Tourism. Madrid: World Tourism Organization.

Sari, E. (2019). Akulturasi Budaya pada Masyarakat Etnis Tionghoa di Kota Sibolga. Medan: Universitas Sumatera Utara.

Soegihartono. (2015). Pengaruh Akulturasi Tionghoa \& Jawa Dalam Perkembangan Bisnis di Semarang. RESPONS, 20(02), $169-215$.

SuaraMerdeka.com. (2019, September 08). Baca Buku: Jejak Kuliner Tionghoa di Indonesia. Retrieved from SuaraMerdeka.com: https://www.suaramerdeka.com/smcet ak/baca/197187/jejak-kuliner-tionghoadi-indonesia

Sufa, S., Subiakto, H., Octavianti, M., \& Kusuma, E. (2020). Wisata Gastronomi sebagai Daya Tarik Pengembangan Pengembangan Potensi Daerah Kabupaten Sidoarjo. Jurnal IImu Komunikasi, 4(1), 75-86.
Sulistyowati, N. (2016). Studi Literatur: Analisis Teori Bisnis dalam Aktivitas Kewirausahaan. Jurnal Akuntansi dan Pendidikan, 5(1).

Tanico, D. (2016). Melestarikan Minuman Tradisional Khas Jawa Timur sebagai Potensi Pengembangan Wisata Kuliner (Culinary Tourism). Jurnal Pariwisata Pesona, 1(2), 1-6.

Tifada, D., \& Mahabarata, Y. (2020, Juni 03). Pengaruh Orang Tionghoa dalam Sejarah Indonesia: Dari Majapahit hingga Penjajahan Belanda. Retrieved from VOI.id: https://voi.id/memori/6747/pengaruhorang-tionghoa-dalam-sejarahindonesia-dari-majapahit-hinggapenjajahan-belanda

Tim Buku TEMPO. (2015). Antropologi Kuliner Nusantara. Jakarta: Kepustakaan Populer Gramedia.

Tyas, A. P. (2017). Identifikasi Kuliner Lokal Indonesia dalam Pembelajaran Bahasa Inggris. Jurnal Pariwisata Terapan, 1(1), 1-14.

Wardana, B. (2017). Akulturasi budaya masyarakat Tionghoa dengan masyarakat Pribumi di Desa Karangturi, Kecamatan Lasem, Kabupaten Rembang. Semarang: Universitas Negeri Semarang.

Wijayanti, A. (2020). Wisata Kuliner Sebagai Strategi Penguatan Pariwisata Di Kota Yogyakarta, Indonesia. Khasanah IImu : Jurnal Pariwisata Dan Budaya, 11(1), 74-82.

World Tourism Organization. (2012). Global Report on Food Tourism. Madrid: World Tourism Organization.

Yanthy, P. (2016). Kontribusi Perempuan dalam Mengangkat Kuliner Lokal untuk Mendukung Pariwisata Bali. Denpasar: Universitas Udayana.

Yeoman, I., \& McMahon-Beatte, U. (2016). The future of food tourism. Journal of Tourism Futures, 2(1), 95-98.

Yuanzhi, K. (2005). Silang Budaya TiongkokIndonesia. Jakarta: Bhuana IImu Populer (BIP). 